\title{
The influence of cultural capital and mianzi (face) on mature students' orientation towards higher education in China
}

\author{
Shanshan Guan (first author)
}

Faculty of Arts Cultures and Education, University of Hull, Hull, England, United Kingdom

Josef Ploner (second author)

Faculty of Arts Cultures and Education, University of Hull, Hull, England, United Kingdom

Corresponding author: Shanshan Guan, Faculty of Arts Cultures and Education, University of Hull.

Contact details: shanshanguan0123@gmail.com/ Shanshan.guan@ 2014.hull.ac.uk

This is an Accepted Manuscript of an article published by Taylor \& Francis in Compare: A Journal of Comparative and International Education on $18 \mathrm{Jul} 2018$ ], available online:

https://www.tandfonline.com/doi/full/10.1080/03057925.2018.1490999 


\title{
The Influence of Cultural Capital and Mianzi (Face) on Mature Students' \\ Orientation towards Higher Education in China
}

\begin{abstract}
In the wider context of national growth and investment in higher education in China, more mature students seek to gain access to university education. Considering the farreaching socio-economic and political shifts in contemporary China and its higher education sector in particular, this study explores the experience of mature university students in this country and poses the seemingly simple question as to why these students did not pursue higher education when they were school-leavers, but chose to study at a mature age. Drawing on biographical interviews with 20 Chinese mature university students, the paper explores their aspirations, motivations and tribulations behind embarking on higher education. Revisiting Bourdieu's ideas on 'inherited' and 'acquired' cultural capital and examining the related Chinese cultural notion of mianzi ('face'), it is argued that family and social networks are decisive factors in mature students' orientation towards higher education.
\end{abstract}

Key word Mature students; higher education; China; cultural capital; mianzi; face 


\section{Introduction}

It has widely been argued that cultural capital (or the perceived lack of it) is tightly intertwined with access to, and success in, higher education (Reay et al., 2009; Reay, 2004; Xu and Wang, 2010). Many studies claim that insufficient inherited cultural capital is a key reason for students' absence and attrition from higher education (Reay et al., 2002; Reay, 2011; Winkle-Wagner, 2010). Likewise, there is evidence to suggest that students with insufficient inherited cultural capital actively seek to participate in higher education in order to gain additional knowledge and resources, which act as cultural capital acquired from interactions with other knowledgeable individuals or groups (Tierney and Venegas, 2009; Walker, 2014).

Frequently defined as 'non-mainstream' or 'disadvantaged', mature students have received a fair amount of attention in the Anglophone literature, where authors have examined the manifold ways in which cultural capital impacts on their motivation and transition to higher education (Swain and Hammond, 2011; Fragoso et al., 2013). A majority of studies claim that cultural capital is derived from students' family and social backgrounds and determines their participation and success in higher education. It is also well documented that (mature) students who represent the first generation in higher education in their families tend to encounter more difficulties in being recruited than students whose parent(s) hold a university degree (Crozier et al., 2011; Dumais and Ward, 2010; Gofen, 2009). 
Whilst there is a wealth of studies exploring adult education in 'western' (i.e. Anglophone) countries, fairly little is yet known about the experience of adult students and/or mature learners in China. In order to address this gap in research, this article poses the seemingly simple question as to why these students did not pursue higher education when they were school-leavers, but chose to study at a mature age. It envisages the influence of cultural capital on Chinese mature students' orientation towards, and participation in, higher education by considering specific, and often problematic, intergenerational dynamics and socio-political contexts. These, in turn, relate to recent Chinese history which saw parents grow up during the Cultural Revolution (1966-1976) while their children grew up during the one-child policy period (1979-2015). In the following sections, both the Cultural Revolution and the one-child policy will be introduced as significant historical events that impacted on higher education participation in China. Together with a subsequent discussion of cultural capital and its Chinese equivalent 'mianzi' ('face' or 'status'), this will help to contextualise the complexities that characterise higher education participation for adult students.

\section{Intergenerational frictions in assessing the value of higher education in China}

In present-day China, only a small percentage of students are admitted to university, leading to increased competition in accessing higher education. Despite a much reported massification of higher education in the country over the past two decades, opportunities of being recruited by an elite or a so-called 'national key university' remain limited (Mok et al., 2016; Mok, 2016). As a consequence, a great amount of 
pressure is placed on families as many parents expect their children to join the competition and demonstrate outstanding educational achievements, from pre-school to university level (Hong and Zhao, 2015; Wu, 2012). The increasingly competitive nature of education in China is amplified by two historical and socio-political circumstances that affect families and intergenerational relations: the first is parents' frequent regret of having missed out on educational opportunities themselves, caused by educational policy made during China's Cultural Revolution (Wu, 2008); the second is related to China's strict birth control measures, better known as one-child policy (Ren and Edwards, 2017).

During the Cultural Revolution (1966-1976), China underwent enormous political and social change that heavily impacted on Chinese education (Sun, 2008). In this context, adult education was primarily utilised as a political tool aimed at reinforcing ideological indoctrination in the class struggle-centred one-party state (Qi and Tang, 2004). The death of Mao Zedong in 1976 marked the end of the Cultural Revolution and saw Deng Xiaoping emerge as new party leader in 1978. Under his leadership, the guiding principles of Chinese education were mapped out, which paved the way for the restoration and recovery of the Chinese education system, including higher education. In hindsight, the great suspension and political instrumentation of education in the decade between 1966 to 1976 has caused great interruption and deficiencies in schooling and higher education for the people of this generation (Sun, 2008; Wu, 2008).

China's strict birth control policy was initiated in the late 1970s and came into full force in 1982 (Veeck et al., 2003). From this time onwards, the one-child policy was rigidly 
implemented, for example by imposing drastic sanctions against parents who did not conform. Having only been phased out recently (2015/2016), the socio-economic consequences of the one-child policy can only be fully assessed over years to come. From an educational perspective, however, the policy has created a highly competitive environment in that many single children came to bear the entire hopes and future aspirations of families, which in turn lead to high expectations with regards to educational and economic achievements (Long and Pang, 2016).

Greatly affected by the one-child policy, many Chinese parents of today consider higher education for their children to be the most effective route towards economic success in the expanding market economy (Mok et al., 2016; Mok, 2016). This perception is coupled with parents' own regrets of having lost out on educational opportunities during the Cultural Revolution period. As a consequence, many parents tend to develop high expectations for their children while possessing limited understanding of what higher education participation actually means (Heberer, 2009; Long and Pang, 2016). Along with China's strict birth control policy, the pressure on single children to succeed in (higher) education has become a critical inter-generational and socio-political issue (Veeck et al., 2003; Ren and Edwards, 2017). At the same time, it has also reinvigorated the significance of adult (higher) education as an alternative or 'second chance' pathway for mature learners to achieve, or 'catch up' with, educational, social and economic success. 


\section{The Adult Higher Education System (AHES) in China}

At present, there are two main 'parallel' forms of higher education systems in China: the regular higher education system (RHES) and the adult higher education system (AHES) (Yu, 2006, 2010; He, 2012). RHES mainly targets 'traditional' young students who transition directly from high school and are recruited by universities via the Higher Education Entrance Examination. In contrast, the AHES in China refers to university campus-based study leading to a first-degree diploma awarded to working adults. Not dissimilar to many adult education systems in western countries, adult higher education (AHE) in China has long been recognised as a means for upskilling the work force and promoting the expansion of higher education (He, 2004; Liu, 2006). Primarily regarded as professional skills development, an AHE degree is less academically-oriented and thus tends to be less 'valued' than a regular higher education (RHE) degree (Le, 2014; Lu, 2014). Unlike many western adult education systems, where mature students make up a highly diverse group of learners (HESA, 2018), mature university students in China are generally limited to those who have failed or opt out of the Higher Education Entrance Examination (Le, 2014; Yu, 2010). Due to work and family commitments, it is challenging for mature learners to prepare for, or pass, this high-stake exam, especially for those who have already failed it once. Equally, the RHES only offers fulltime courses which mature students cannot commit to because of the same job and family-related reasons (Qin, 2016; He, 2012).

Due to the fact that AHE is still widely regarded more 'vocational' and 'inferior' compared to 'traditional' academic higher education, the degrees awarded within the 
AHES tend to be only marginally beneficial for the students regarding job prospects and career opportunities. Moreover, adult learners are frequently confronted with discriminatory social preconceptions relating to their educational status within an increasingly high-achieving and success-oriented Chinese society (Yu, 2006, 2010; Li, 2015; Qin, 2016). In this environment, education has been identified as a key determinant of labour market access in China and the impact of university qualifications on social status and career development has become hugely significant (Wang and Morgan, 2009; Mok, 2016). But the expansion of higher education has led to the stratification of both higher education institutions and students (Mok, 2016) where graduates from AHES could benefit in terms of income increase or career promotion. However, evidence shows that they still struggle to compete with the graduates from RHES on the wider labour market (Wang and Morgan, 2009).

Within this increasingly competitive Chinese education environment, societal judgments relating to adult students' lower social and cultural capitals, as well as their seemingly insufficient educational histories, have a profound impact on how they see themselves and their educational futures and career prospects. It is against this backdrop, that the prevailing issues of 'cultural capital' and its Chinese equivalent of mianzi (literally meaning 'face', but also 'prestige', 'honour' or 'self-worth') will be discussed in greater detail in the following section. 


\section{Cultural capital and participation in higher education}

French sociologist Pierre Bourdieu $(1974 / 1984 ; 1977$; 1986) states that cultural capital (i.e. as embodied, objectified and institutionalised), can be both inherited or acquired by individuals to help position themselves in particular, and generally 'accepted' social contexts. As for inherited cultural capital, Bourdieu $(1977,1986)$ posits that this cannot be separated from the person who holds it but is embedded in one's thinking and actions and derived from certain norms, rules, social structures and class positions (WinkleWagner, 2010). However, Bourdieu (1986) asserted that individuals can become reflective of their limited inherited cultural capital, and then respond by acquiring more of the kind of capital that is valued in a particular social context. 'Acquired' cultural capital is thus inherited cultural capital altered and extended by one's aspirations and expectations of educational participation, and/or additional knowledge gained through relationships, memberships and networking.

Whilst Bourdieusian 'cultural capital' is a familiar theoretical framework in Anglophone higher education research, it remains largely underrepresented in Chinese academic literature. To some extent, this lack of representation has been associated with the socialist, and seemingly collectivist, Chinese political system, where Bourdieusian ideas of habitus and distinction, cultural capital and reproduction, as well as classrelated educational inequalities, have been deemed irrelevant (Wu, 2008). However, scholars have refuted this simplistic argument by referring to domestic financial status, parental educational level, geographical and ethnic minority status and gender as significant indicators for social and educational inequalities (Wang, 2009; Wang, 2013; 
Lu, 2012; Wang and Jiao, 2016). Others (Guo and Min, 2006; Xu and Wang, 2010; Zhong and Zhang, 2011) have used the concept of cultural capital to address variations in young peoples' expectations of higher education as well as different levels of support they receive from their parents and families. They found, perhaps unsurprisingly, that parents with higher educational qualifications are much more supportive in guiding their children to and through higher education compared to parents with lower educational credentials. As Zeng (2009) argues, even in the recent era of rapid higher education expansion in China, the uneven distribution of both financial and cultural capital across families and communities in the country remains the most pertinent reason for the widening inequality in higher education participation. To date, there is little evidence to suggest that the seemingly rising opportunities for lower-income families, brought along by the one-child policy and growing economic prosperity in the recent past, have significantly narrowed this gap.

Despite an increasing number of critical voices addressing the link between cultural capital and educational inequalities in China, there is an apparent lack of research in exploring the ways in which cultural capital influences motivations, aspirations, and educational practices of mature and/or so-called 'non-traditional' students. Besides, the application of 'western' Bourdieusian approaches to cultural capital, social class and educational inequalities in China often fails to account for the historical, political and cultural complexities that characterise Chinese society today, such as higher education policy making and the emergence of new educational cultures modelled around Confucian values and traditions (Marginson, 2011; Ryan and Louie, 2009). In order to shed further light onto the complexities that determine the relationship between societal 
status and higher education participation in China, the following section outlines the culturally specific notion of mianzi (literally meaning 'face'), which shows some striking parallels to 'western' conceptions of cultural capital based on class and social status.

\section{Chinese 'mianzi' culture and higher education participation}

Gries (1999) describes mianzi as a 'code of honour' that can reveal how face can be 'lost' and/or 'gained' in relation to particular social achievements and circumstances. As a Chinese variation of cultural capital, King (1991, p. 63) notes that mianzi is '...like having good credit, so that one has a lot of purchasing power.' Importantly, mianzi is reciprocal in that it is regarded a shared social responsibility not to damage the reputation and dignity of others: 'it is an intangible form of social currency - 'group credit' - that the whole community seeks to maintain.' (Chen, 2001, p. 72-73). In a similar vein, Ting-Toomey and Kurogi (1998, p. 187) define mianzi as '...a claimed sense of favourable social self-worth that a person wants others to have of her or him [that] can be enhanced or threatened in any uncertain social situation.' The reciprocal and collective nature of 'face' culture in China is underpinned by Confucian values which put family and community relations centre stage. As such, it runs counter to 'western' (i.e. post-Enlightenment) beliefs that each person is an independent and autonomous entity, which does not necessarily assume responsibility for the behaviour of proximate others (Ho, 2016). 
Whilst one might recognise similarities between the notion of 'inherited cultural capital' and mianzi (e.g. in relation to family and intergenerational ties, wealth or social connections), 'face' is equally achieved through 'acquired' personal qualities and achievements such as knowledge, ability, education, etc. In this reading, 'higher' educational qualifications and accolades, as the institutionalised state of cultural capital claimed by Bourdieu, have become increasingly significant markers for gaining mianzi in Chinese society. This goes hand in hand with the Chinese current higher education massification policy and is equally influenced by the social pressures one-child families experience in gaining, retaining and passing on 'face' to the next generation. One could go as far to argue that the higher the educational qualification, the more mianzi could be derived to individuals and families. In view of the increased significance of (higher) education as a marker of social status in Chinese 'face' culture, surprisingly little has been written about this relationship, especially in regards to mature students.

Although one has to be extremely cautious in avoiding generalisation when translating the complexities of Chinese mianzi culture into 'western' (Bourdieusian) notions of cultural capital, there are some striking parallels when it comes to assessing the role of education in gaining social status and prestige. For Chinese families, the educational qualifications of their children may augment their social standing, which, in turn, may lead to increased expectations (if not pressures) for their children to aim high. Conversely, low qualifications and educational failures may instil feelings of shame and 'losing face' for Chinese families and parents. For adult/mature students, who are often the first in their families to attend university, higher education credentials may 
thus mean an increased sense of mianzi that breaks with inherited family cultural capitals and 'traditions', and thus impacts positively on their social status.

The review of literature on Chinese AHES, social and educational inequalities and the related notions of cultural capital and mianzi, shows that there is still a wide gap to fill in assessing the multiple experiences of mature students in their way to and through present-day Chinese higher education. Addressing this gap, the study presented here aims to explore how families' and parents' social dispositions influence students' orientation towards higher education, and to appraise how socio-cultural factors such as mianzi impact on their educational aspirations and experiences.

\section{Research methodology}

This qualitative study employs a biographical interview approach, which is seen as appropriate to gain insights into the past and present experiences of mature HE students, along with the contextual settings within which phenomena such as mature higher education learning occur (Roberts, 2002). A large first-tier city along the eastern coast has been selected as a suitable location for this research, since China's coastal urban belt is widely regarded as the economic and educational 'powerhouse' of the country. Within this city, two universities (one funded by central government and one funded by provincial government) have been selected according to a criterion-based purposeful sampling technique, through which both reliable and accessible data about mature students were gathered (Eisner, 1991). 20 mature students (10 at each university ) have been purposefully selected according to the following criteria: a) they are only children 
(i.e. parents complied with the one-child policy); b) they are the first in their family to attend university; and c) their parents possess limited educational qualifications (i.e. school leaving certificate or similar) and have low to medium income occupations. Due to the self-selective sampling, it happened that all research participants were female and covered an age range between 28 and 40 years. At the time of interviewing (2016), most participants were working full-time, married and had their own children. The interviews were recorded and transcribed verbatim, and the transcripts were screened and analysed with the support of the Nvivo software tool. By rigorous coding, certain themes emerged, which will be discussed in the following research findings.

\section{Findings}

In this section, some of the narratives emerging from the biographical interviews with mature students will be presented, with a particular focus on their views on inherited cultural capital and acquired cultural capital. While students reflect on their individual educational careers, they also highlight how parents' expectation and support, as well as their wider social and occupational networks, have influenced their higher education aspirations. The analysis of interview data reveals some key themes emerging from mature students' narratives: parents' mianzi-oriented expectation for their educational careers; insufficient parental support for their educational careers; and mature students' acquired cultural capital via social and professional networks in support of their educational careers. 


\section{Parents' Mianzi-oriented Expectation for Children's Educational Careers}

Parents' expectations and support play a hugely important role in enabling their children to participate in higher education (Sullivan, 2001; Winkle-Wagner, 2010). As for China, existing studies show that single children bear great expectations and pressure from their families in terms of educational and career success, since parents tend to treat their only child as the cornerstone on which the reputation and future of the family rests (Huang and Wen, 2008; Tian and Liu, 2014). The following statement reveals some of the expectations and motivations parents project on their children in view of higher education participation.

In my parents' mind, having a degree means you can have a good job and it is the key to have a good job. As parents, children having [a] degree could make them feel proud in front of their friends. These two are the main reasons why my parents want me to have a degree. (age of 35, single, graduated)

The narrative above clearly highlights the two main reasons as to why parents want their children to attend university, which are a good job for their child as well as dignity (mianzi) for the parents themselves. Similarly, the following statement is representative of the overall research sample and re-emphasise parents' main expectations of and influences on their children in terms of higher education participation:

Since my parents have not got much education so they feel a degree [is] just a tool for you to get a good job. Otherwise you cannot have a decent job or have a satisfying salary. (age of 30, single, first year student) 
The quote above illustrates that the mature students recognize that in their parents' mind, gaining a higher education degree is equivalent to being able to find a good, and financially lucrative, job. It reveals that mature students associate their parents' partial understanding of higher education with the limited education they have received. This is a recurrent theme in most of the interviews and shows that mature students are conscious of the fact that their parents are not fully aware of the comprehensive functions of higher education, but only tend to apprehend the material benefits of higher education as linked to a better-than-average job and salary. The following accounts by two female mature students in their 30s highlight another important aspect driving their parents' expectations and motivations:

Since I was little, my mum wanted me to have a good performance in my study, because that would make her feel gratified and proud. My mum felt really 'losing mianzi' when she talked with other people about how [well their] children performed in the Higher Education Entrance Examination since other people's children could go to university, but I failed when I was 18. (age of 33, married, second year student)

There have been more and more people owning a degree in China. It could be a shame for my parents when they talk with other people if other people's children have a degree but I do not. It is the success of parents for [their] children to have a degree and a good job. (age of 32, single, graduated) 
Dignity and reputation (mianzi) towards friends and other family members is another key factor that drives parents to encourage their children to go to university. This is clearly addressed in the above quotes which emphasise parents' pride or embarrassment when sharing stories about their children's educational successes or failures with others. As reflected in most of the interviews, 'having face' or 'gaining face' are two prevalent, if subtle, cultural practices among Chinese people that define their relation to, and social standing among, others. Here, one's success does not merely mean the realization of individual goals and achievements, but generates dignity and reputation for the wider family. In fact, as Wang et al. (2013) note, 'gaining face' has more value than achieving self-realization. Interestingly, many mature students in this research mentioned that, by comparing them with educationally better achieving children, parents used mianzi to exert pressure on them to work harder so as to avoid 'losing face'.

The data presented so far illustrates that the mature students participating in this study think that their parents have high expectations when it comes to educational success and higher education participation. This is bound up with the perception that a higher education degree will augment job prospects and equip children with the necessary skills to negotiate the increasingly competitive Chinese labour market. While keeping or gaining 'face' is a major socio-cultural component in this generational interplay, students emphasise that their parents' understanding of (higher) education is relatively limited which does not help when it comes to supporting them in their educational endeavours. The following section sheds further light onto the lack of support students experience in their journeys towards higher education. 


\section{Insufficient parental support for children's educational careers}

As highlighted in previous studies, parents' support and involvement in their children's education is a significant indicator of cultural capital within families and has a significant impact on children's educational performance and success (Reay et al., 2009; Reay, 2004; Xu and Wang, 2010). The findings presented in this section reveal that, although nearly all of the mature students' parents in this study project high expectations onto their children, they offer minimal support and guidance when it comes to nurturing their educational aspirations. Here is what two female students in their early 30s have to say:

My parents have been very strict with my study since I was little. But they have not got much education themselves so the way they managed my study was giving me requirements and punishing me if I could not meet their requirements. If I fail they would be upset and shouting at me but they do not have the idea to give me guidance and help. (age of 32, married, first year student)

My mum has been given me a lot of requirements and demands on my study since I was little, but she never asked if I needed help and she never gave me guidance on my study. She would always say: 'have a look at other children! Why do they have a higher score than you?', but she never saw what their parents have done for helping their children, and she never realized that all she gave me were requirements and punishment. (age of 31, married, first year student) 
The above statements are representative of most interviewees' experiences. The majority of interviewed students revealed that their parents were predominantly inclined to command and punish them, rather than offering constructive support and guidance. Although the interviewees were aware that this lack of support was mainly due to their parents' poor educational backgrounds, they also regretted the absence of parental support which is linked to their parents' lack of cultural capital. As a consequence, many students remember feelings of 'panic', 'failure' or 'low self-esteem' during their time at school.

Whilst many parents sought to spur their children's educational success by means of continuous authoritarian interventions, a good number of interviewees indicated that their parents showed little to no interest when it came to their educational experiences. Reflecting on her time at school, a mature student in her late 20s states:

My parents did not care about my study when I was in school. They cared only about the result rather than the process heading to the expected result. I signed all the sheets that teachers asked the parents to sign since they did not care. They did not even know much about education so they had no idea which college was better or which major I should choose. They just did not know and neither did they care. (age of 29, married, graduated)

Apart from this interviewee, most of the other mature students recalled similar situations and experiences. In particular, parents' emphasis on results and their indifference towards children's study process were frequently mentioned as key reasons 
for insufficient orientation and guidance. Merely giving their children the ultimate 'commandment' of gaining higher education access, they showed little awareness of what effort should be made to achieve that goal. Some interviewees also noted that their parents chose not to give instructions in order to avoid offering potentially 'wrong' or inappropriate guidance. Regardless of the reasons behind parents' lack of support and understanding, the mature students claimed that their parents' poor understanding of, or indifference towards, their education was an important reason why they failed to enter higher education through the 'traditional' route at a younger age. The narrative below illustrates mature students' frustration and regret, especially the feelings of "losing-face" and inferiority as a mature student and, likewise, as employees:

Being a mature student in this era means you are the eliminated from the RHE, which is losing-face. When we find a job, the employers differentiate us from those who have the full BA honours' degree from RHES. We feel self-abasement and self-inferiority. But study as mature students is the only way we could choose due to our family and job commitment. (age of 34 , third year student)

The above quote provides unique insights into the personal struggles of mature students to 'keep face', not only towards parents, students in the regular HE system, and employers, but perhaps most importantly towards themselves in terms of selfconfidence and valuing their personal achievements. Having explored mature students' experiences linked to inherited cultural capital within their families, the following sections outline their experiences of acquiring cultural capital from alternative 
individuals, sources and social environments, which has helped them to pursue higher education.

\section{Mature Students' acquired cultural capital as a pathway to higher education}

As outlined above, acquired cultural capital can be defined as the knowledge and ability that people gain through their own efforts (e.g. work or education) or by taking inspiration from the life experiences of others which contrasts, extends, or complements their own inherited cultural capital (Bourdieu, 1986). Based on Bourdieusian notions of cultural capital, acquired cultural capital could thus be built around individual's aspirations, worldviews and skills based on social interactions and knowledge exchanges with others (Walker, 2014; Tierney and Venegas, 2009; Kim, 2010).

A particular theme that emerged strongly from the interview data was that mature students were inspired and encouraged to enter higher education by their work colleagues and the professional atmosphere around them. Through their daily work environment, they gradually realised that many of their colleagues have equally sought the opportunity to improve themselves, especially through a university degree. This positive atmosphere, encouragement, and role-modelling from others represents a stark contrast to the controlling and ill-informed parental advice they were exposed to earlier in their lives. For example, this experience is evidenced by a 34-year old student who states:

The atmosphere in my workplace pushes me to have a degree and improve myself. Since a lot of my colleagues have studied in university as mature students, you do 
not want to be left behind and you would be inspired to do as well as other people. (age of 34, married, graduated)

In addition to being inspired by other people's experiences and life stories, mature students' own life situation also pushes them to seek a better living situation. Here, the notion of mianzi is often implicit in that mature students associate educational growth and success with changing family situations and responsibilities. This change of perspective and attitude is reflected in the following narrative:

My previous job took too much of my personal time. After I had my little girl I realized I could not live this life any more since I have to spend more time looking after her. My little girl is my priority in my life so I decided to get a degree and change a job. I want to have a decent job and give her a good environment to grow up. (age of 31, married, first year student)

Since all the volunteer interviewees in this research are female, many of them mentioned that after having their own children they were more eager to providing a better living situation for their children, which pushed them to seek access to a degree programme. This motivation for gaining a higher education qualification has not been encouraged or imposed by other people but is subject due to individual considerations and efforts to enhance one's occupational and personal life circumstances, and with that, mianzi. Although not explicitly voiced by the interviewees, their renewed motivation to embark on higher education as a means to negotiate family and work duties may well 
be read as a process of compensation for lost opportunities due to poor parental guidance and support.

A particular theme that emerged most frequently from the interviews is that the majority of the participants proactively approached work colleagues or friends in order to gain useful guidance and information on higher education study. This strategic approach is reflected in the following statements by two mature students:

My colleagues told me the procedure and process of applying at the university and taking the entrance exam. They gave me the materials they have used last year for preparing for the entrance exams. (age of 29, married, third year student)

My friend has helped me a lot with the entrance exam. Since she had done it herself she knows the whole procedure and she tells me how to prepare for the entrance exam and how to select [the] university. (age of 31, single, third year student)

The narratives above demonstrate how the provision of direct information and help by other people can guide mature students to apply to the university and maximise their chances to be recruited. Rather than asking help or guidance from other persons directly, mature students also learn, and imitate, certain behaviours from their friends:

I have witnessed how my friends study as mature students. I know it is not difficult to study in university as mature students and I just feel I can do it as well. I know 
how to study as mature students from their experience even without asking them for help directly. (age of 28, single, graduated)

According to this and most other narratives, mature students' further life experiences and encounters with others increased their self-confidence to become mature university students. Mature students interviewed for this research claim that it was quite important for them to know that they are able to study at university. Combined with the rolemodel effect that others exert on them, this self-confidence is significant for mature students to take the further step of garnering more information on how to select, apply and study for a degree course. In this context, consciously observing and mimicking other people's experiences contribute to renewed aspiration and re-found selfconfidence, which assists mature students to put the goal of 'going to university' into actions.

\section{Discussion}

Coined by Bourdieu (1986), 'cultural capital' has been applied as a key theoretical framework by a legion of educational researchers to make sense of the manifold ways in which individuals or social groups meet expectations, develop aspirations and seek participation in (higher) education. In this context, 'inherited' and 'acquired' cultural capital are two commonly used concepts that determine access, attainment and success in higher education. The narratives presented in this study clearly reveal that many Chinese mature students attribute their previous 'losing out' on higher education to the lack of 'inherited' cultural capital within their families. In their view, the lack of formal 
education (and particularly higher education) in their domestic environment was among the main reasons for receiving poor immediate support during their upbringing. In addition, the frequent lack of understanding and empathy of education from parents growing up during the 'Cultural Revolution' period often collides with the aspirations and future plans of their single children. Nearly all the interviewees claim that their parents set high educational stakes for them while possessing no, or extremely limited, knowledge about the basic requirements and affordances bound up with higher education participation. Parents' authoritarian demands towards their children to gain higher education qualification, are tied in with their own interests in augmenting or retaining 'face' within their proximate social environment. However, in the course of their professional careers and personal lives, these individuals seek to 'acquire' cultural capital from others, which helps them to orient themselves towards 'going to university', and further, towards potential upward social mobility. Yet, as some of the narratives reveal, even in these instances 'face' remains an important reference point for students who seek to 'prove' themselves to others or 'feel pushed' to succeed in their educational endeavours.

The presented research findings also suggest that aspirational students adopt two main, and often combined, strategies to pursue the goal of higher education, i.e. by actively seeking the help and support beyond their families from colleagues and friends, or indirectly observing and mimicking the practices of others. These strategies for 'acquiring' cultural capital are played out when mature students think about their past, present, and especially future opportunities towards upward social mobility (Archer, 2007). These reflective strategies are reminiscent of what Stevenson and Clegg refer to 
as the formation of 'possible selves' which determine mature students' individual orientations towards desired possibilities while carefully devising actions that help evade less-desirable futures (Stevenson and Clegg, 2013, p.19). However, the reflexive and individualistic projects that mature students may develop in the global west (i.e. the UK in Stevenson' and Clegg's study), do not necessarily translate into Chinese educational contexts, where students have to continually negotiate social and cultural expectations associated with Confucian idea(l)s of family and traditional (if increasingly challenged) notions of collectivism. To this end, this study generates valuable insights into the ways in which Chinese mianzi culture corresponds with educational achievement (or failure) and draws attention to the significance that 'gaining', 'keeping' or 'losing face' has for all agents involved. As the majority of interviewees made clear, 'keeping face' has played an important role in their educational pasts, and more often than not, has exposed them to domestic and societal pressures, or caused frustration, disenfranchisement and low self-esteem when it came to fashioning their future selves. Furthermore, mianzi continues to heavily influence their experiences as mature university students when new family and professional responsibilities as employees, spouses, parents and carers come into play and demand ever-new strategies for achieving (or maintaining) social recognition and status.

Regarding the significant efforts these mature learners make in acquiring cultural capital and mianzi through higher education, it is regrettable that AHE in China is not highly regarded in society and mature students are in many ways disadvantaged. This is particularly problematic in a rapidly accelerating and competitive Chinese higher education environment, which sees young, high-achieving, school-leavers as the 'gold 
standard' and thereby discriminates against those who do not necessarily fit into this category ( $\mathrm{Li}, 2015)$. The mere physical segregation of 'traditional' and 'mature' students on Chinese university campuses can be seen as an apt indicator of this prevailing inequality. Indeed, the relatively poor reputation of AHE in China and the segregation between 'traditional' and 'adult' students can be seen as indicative for greater socio-economic transformations in contemporary China which challenge historical values of collectivism, educational participation and equal opportunities for all. This is also reflected in Mok's (2016) assessment that massification, i.e. the increased access to higher education over the past two decades, has not necessarily meant increased upward social mobility for graduates but are characterised by severe stratification that often discriminates against mature students. Seen from a different perspective, however, one could draw some parallels to experiences of mature students in many 'western' (e.g. Anglophone) universities, who, according to Mallman and Lee (2016), often go through similar experiences of educational stigmatisation.

\section{Conclusion}

From a theoretical perspective, this small yet revealing study highlights both the strengths and limitations of 'inherited' and 'acquired' cultural capital as flexible concepts, well-suited and applicable to a wide range of social and cultural settings. However, as it is predominantly applied to western educational milieus, 'cultural capital', in Bourdieusian diction, cannot always do justice to the historical, cultural, political, and societal complexities that permeate notions of class, kinship, and equality of opportunity in non-western contexts. To this end, the notion of mianzi or 'face' has 
provided a useful conceptual complement in making sense of mature students' educational experiences in contemporary China. Whilst considering the pitfalls of cultural universalism when comparing and translating different cultural expressions, future research should not shy away from seemingly unfamiliar philosophical concepts and critical cross-cultural dialogue that may help to shed light on educational inequalities worldwide.

Through biographical interviews with mature students in China, this study has produced some insightful findings as to how these individuals negotiate their access to, and participation in, higher education. Students' narratives clearly show that they tread a fine line between family expectations, social stigmatisation, educational segregation, and their personal aspirations as 'future selves'. Although the biographical method is not without flaws in terms of generalisability, it has generated valid findings that allow for a close reading of individual motivations whilst highlighting a particular set of experiences shared by a wider group of participants. The limitation of the biographical approach, at least in this study, relates to the limited number of participants in two universities in a major city in East China. However, it is hoped that the rich evidence gathered in this study, will stimulate further research into the hitherto much-overlooked area of AHE in China. For example, future studies could envisage how increasing socioeconomic disparities between east and west, urban and rural affect (adult) higher education in the country today, or further explore the role that gender, ethnicity and, indeed, age play in forging educational and career-related aspirations among mature students. 


\section{References}

\section{English literatures:}

Archer, M.S. 2007. Making Our Way through the World. Cambridge: Cambridge University Press.

Ball, S. J., Davies, J., David, M., and Reay, D. 2002. “'Classification' and 'Judgement': Social Class and the 'Cognitive Structures' of Choice of Higher Education." British Journal of Sociology of Education 23(1): 51-72.

Bourdieu, P. 1977. Outline of a Theory of Practice. Cambridge: Cambridge University Press.

Bourdieu, P. 1984. Distinction: A Social Critique of the Judgment of Taste. (R. Nice, Trans.). London: Taylor and France: Routledge. (Original Work Published 1974)

Bourdieu, P. 1986. "The Forms of Capital." In Handbook of Theory and Research for the Sociology of Education, edited by J. G. Richardson, 241-258. New York: Greenwood Press.

Chen. G. M. 2001. "From Sorry to Apology: Understanding the Chinese." Chinese Community Forum July II. no. 27. doi: http://www.china-net.org.

Crozier, G., James, D., and Reay, D. 2011. "Making It Work for Their Children: White Middle Class Parents And Working Class Schools." International Studies in Sociology of Education 21(3):199-216. dio: 10.1080/09620214.2011.616343

Dumais, S. A., and Ward, A. 2010. "Cultural Capital and First-Generation College Success." Poetics 38(3): 245-265.

Eisner, E. W. 1991. The enlightened eye: Qualitative inquiry and the enhancement of educational practice. New York: Macmillan Publishing Company.

Fragoso, A., GonÇAlves, T., Ribeiro, C.M., Monteiro, R., Quintas, H., Bago, J., Fonseca, H.M. and Santos, L. 2013. "The transition of mature students to higher education: Challenging traditional concepts?" Studies in the Education of Adults 45(1): $67-81$.

Gofen, A. 2009. "Family Capital: How First-Generation Higher Education Students Break the Intergenerational Cycle." Family Relations 58(1): 104-120.

Gries, Peter Hays. 1999. “A 'China Threat?' Power and Passion in Chinese 'Face Nationalism'.” World Affairs 162(2): 63-75. 
Heberer, T. 2009. "The 'Great Proletarian Cultural Revolution': China's Modern Trauma." Journal of Modern Chinese History 3(2): 165-181.

Higher Education Statistics Agency (HESA). 2018. "Who's studying in HE?" (online) Available at: https://www.hesa.ac.uk/data-and-analysis/students/whos-in-he. Accessed February 2018.

Ho, Benjamin, and Tze Ern. 2016. "About Face - The Relational Dimension in Chinese IR Discourse." Journal of Contemporary China 25(98): 307-320.

Hong, Yanbi, and Yandong Zhao. 2015. "From capital to habitus: class differentiation of family educational patterns in urban China." The Journal of Chinese Sociology 2(1): 18.

Kim, J. 2010. "The Effect of Prices on Postsecondary Access: An Update to Heller." Higher Education in Review 7: 23-46. dio: http://www.clubs.psu.edu/up/hesa/her/

King, Ambrose and Yeo-Chi. 1991. "Kuan-Hsi and Network Building: A Sociological Interpretation." Daedalus 120(2): 63-84.

Long, H., and Pang, W. 2016. "Family Socioeconomic Status, Parental Expectations, and Adolescents' Academic Achievements: A Case of China." Educational Research and Evaluation 22(5-6): 283-304.

Marginson, S. 2011. "Higher education in East Asia and Singapore: rise of the Confucian model." Higher Education 61(5): 587-611

Mallman, M. and Lee, H. 2016 "Stigmatised learners: mature-age students negotiating university culture." British Journal of Sociology of Education 37(5): 684-701

Mok, K. H. 2016. "Massification of higher education, graduate employment and social mobility in the Greater China region." British Journal of Sociology of Education 37(1): $51-71$.

Mok, K. H., Wen, Z., and Dale, R. 2016. "Employability and mobility in the valorisation of higher education qualifications: the experiences and reflections of Chinese students and graduates." Journal of Higher Education Policy and Management 38(3): 264-281.

Noble, J., and Davies, P. 2009. "Cultural Capital as an Explanation of Variation in Participation in Higher Education." British Journal of Sociology of Education 30(5): $591-605$

Qi, W. and Tang, H. 2004 "The Social and Cultural Background of Contemporary Moral Education in China." Journal of Moral Education 33(4): 466-480.

Reay, D. 2004. "Education and Cultural Capital: The Implications of Changing Trends 
in Education Policies." Cultural Trends 13(2): 73-86.

Reay, D., Ball, S., and David, M. 2002. “'It's Taking Me a Long Time but I'll Get There in the End': Mature Students on Access Courses and Higher Education Choice." British Educational Research Journal 28(1): 5-19.

Reay, D., Crozier, G., and Clayton, J. 2009. “'Strangers in Paradise'? Working-Class Students in Elite Universities." Sociology 43(6): 1103-1121.

Reay. D. 2011. “Schooling for Democracy': A Common School and a Common University? A Response to 'Schooling for Democracy'." Democracy and Education 9(1): 6 .

Ren, L. and Edwards, C.P. 2017. "Chinese Parents' Expectations and Child Preacademic Skills: The Indirect Role of Parenting and Social Competence." Early Education and Development 28(8): 1052-1071.

Roberts, B. 2002. Biographical Research. Buckingham: Open University Press.

Ryan, J. and Louie, K. 2007. 'False dichotomy? 'Western' and 'Confucian' concepts of scholarship and learning." Educational Philosophy and Theory 39(4): 404-417

Stevenson, J. And Clegg, S. 2013. “"My Past Is A Double Edge Sword': Temporality And Reflexivity In Mature Learners.” Continuing Education 35(1): 17-29.

Sullivan, A. 2001. "Cultural Capital and Educational Attainment." Sociology 35(4): 893-912.

Sun, Q. 2008. "The development of Chinese adult education within its social contexts: A review since 1949." Convergence 41(4): 13.

Swain, J. and Hammond, C. 2011. "The motivations and outcomes of studying for parttime mature students in higher education." International Journal of Lifelong Education 30(5): 591-612.

Tierney, W. G., and Venegas, K. 2009. "Finding Money on the Table: Information, Financial Aid, and Access to College." Journal of Higher Education 80(4): 363-388. dio: http://www.ohiopress.org

Ting-Toomey, S. and Kurogi, A. 1998. "Facework Competence in Intercultural Conflict: An Updated Face-Negotiation Theory." International Journal of Intercultural Relations no. 22: 187-225.

Veeck, A., Flurry, L., and Jiang, N. 2003. "Equal Dreams: The One Child Policy and the Consumption of Education in Urban China." Consumption, Markets and Culture 6(1): 81-94. 
Walker, G. J. 2014. A Qualitative Study of How Cultural Capital Affects Low-Income Undergraduate Students' Decisions To Participate in Highly Ranked Research Institutions in The State Of Texas. North-Eastern University.

Wang, Naixia. and Morgan, W.J. 2009. "Student motivations, quality and status in adult higher education (AHE) in China." International Journal of Lifelong Education 28(4): 473-491.

Winkle-Wagner, R. 2010. "Foundations of Educational Inequality: Cultural Capital and Social Reproduction." ASHE Higher Education Report 36(1): 1-21.

Wu, Yuxiao. 2008. "Cultural capital, the state, and educational inequality in China, 1949-1996." Sociological Perspectives 51(1): 201-227.

Wu Xiaoxin. 2012. "The dynamic role of cultural capital in the competitive school admission process: a Chinese experience." The Australian Association for Research in Education 39: 275-293.

\section{Chinese literatures:}

Guo Congbin and Min Weifang. 2006. "The Impact of Family Economy and Cultural Capital on Children's Educational Opportunity." Journal of Higher Education Research no. 11:24-31. 郭丛斌,闵维方. 家庭经济和文化资本对子女教育机会获得的影响 [J]. 高等教育研究, 2006,(11):24-31.

He Hongling. 2004. A Study of Higher adult Education Development since the People's Republic of China. China Social Sciences Press 何红玲. (2004). 新中国成人教育发 展研究. 中国社会科学出版社.

He I'xia. (2012). "The Historical Evolution and Trends of Adult Higher Education Institutions in China.” Modern Distance Education Research no. 4: 21-27. 何爱霞. 我 国成人高等教育办学机构的嬗变及趋向[J]. 现代远程教育研究, 2012, (04): 21-27.

Huang Lin and Wen Dongmao. 2008. "A Comparative Study on the Academic Status of College Students: Only - Child and Non-Only-Child." Journal of Education Monthly no. 2: 36-39. 黄琳, 文东茅. 大学生独生子女与非独生子女学业状况比较 $[\mathrm{J}]$. 教育学 术月刊, 2008,(02):36-39.

Le Chuanyong. 2014. The Research about the Transformative Development of the Chinese Adult Higher Education. Zhejing University Press. 乐传永. (2014). 成人教育 转型发展研究. 浙江大学出本社.

Li Xiaoling. 2015. "A Study on the Development of Adult Education in the Post Popular Times.” Education Teaching Forum no. 13: 62-63. 李晓玲.后大众化时代高 校成人学历教育发展对策研究 [J]. 教育教学论坛, 2015, (13): 62-63. 
Liu Jingming. 2006. "Expansion of Higher Education in China and Inequality in Entrance Opportunities: 1978-2003.” Society 26(3): 158-179. 刘精明.高等教育扩展与 入学机会差异: 1978 2003[J]. 社会, 2006, 26(3): 158-179.

Lu Desheng. 2014. "An Analysis of the Transition of Higher Adult Education in Post Academic Era.” Journal of Continuing Education no. 33:46-49. 卢德生. 后学历时代 高等成人教育转型探析 [J]. 继续教育, 2014, (33):46-49.

Lu Hao. 2012. "The Impact of Family Background on Higher Education Access and Planning." Journal of Contemporary Education Theory and Practice no. 8:30-33. 卢 昊. 家庭背景对高等教育获得及规划的影响 $[\mathrm{J}]$. 当代教育理论与实 践,2012,(08):30-33.

Qin Jianwei. 2016. "The Development Strategy of Adult Higher Education Under the Trend of Higher Education Popularization." Continuing Education Research no. 8: 7072. 秦建伟. 高等教育大众化趋势下成人高等教育发展策略探讨 $[\mathrm{J}]$. 继续教育研究. 2016, (8): 70-72.

Tian Feng and Liu Yulong. 2014. "An Analysis of the Influence of Higher Education on the Differences between the only One Child And the Non - Only One Child." Journal of Population and Economy no. 5: 51-61. 田丰,刘雨龙. 高等教育对独生子女和非独 生子女差异的影响分析[J]. 人口与经济. 2014,(05):51-61.

Wang Dan, Tan Jingjing and Xu Yuhan. 2013. "The Impact of Culture of 'Face' on Students' Behaviour on Their Study." Journal of Education Teaching Forum no. 27:145-147. 王丹,谭敬靖,徐雨函. 面子文化对大学生学习行为影响研究[J]. 教育教 学论坛,2013,(27):145-147.

Wang Like. 2009. "Cultural Capital and Its Influence on Higher Education Opportunity Equality.” Journal of Higher Education Research no. 2:27-30. 王立科. 论文化资本及 其对高等教育机会平等的影响[J].中国高教研究,2009,(02):27-30.

Wang Xiaoyun. 2013. "An Empirical Study on the Acquisition of Chinese Family Cultural Capital and Children's Higher Education." Journal of Evaluation of China's Higher Education no. 4: 49-54.王晓云. 中国家庭文化资本与子女高等教育机会获 得的实证研究 $[J]$. 中国高等教育评估. 2013, (4): 49-54.

Wang Yashuang and Jiao Yicheng. 2016. "A Study on the Factors Affecting the Quality of Higher Education Admission." Journal of Higher Education in Jiangsu Province no. 3: 31-35. 汪雅霜,矫怡程. 高等教育入学机会质量获得影响因素研究 [J]. 江苏高 教,2016,(03):31-35.

$\mathrm{Xu}$ Jiling, and Wang Hui. 2010. "A Study on the Influence of Cultural Capital on the Opportunity of Higher Education Admission-Based on the Perspective of Cultural 
Capital Reproduction.” Journal of Education and Teaching Research no. 5: 29-31.徐 继岭,王辉. 文化资本对高等教育入学机会影响研究一一基于文化资本再生产的 视角 [J]. 教育与教学研究,2010,(05):29-31.

Yu Xiaobo. 2010. A Study on the Transformation of Chinese Adult Higher Education. Hunan University Press. 余小波 (2010). 中国成人高等教育转型研究. 湖南大学出 版社.

Yu Xiaobo. 2006. "An Interpretation of the Concept of Adult High Education.” Journal of Changsha University of Science and Technology (Social Science). no. 4: 121-126. 余小波. 成人高等教育概念的诠释 [J]. 长沙理工大学学报(社会科学版), 2006, (04): 121-126.

Zeng Hua. 2009. "Higher Education: The Path of Cultural Capital Regeneration." Journal of Nantong Vocational College no. 1: 26-31. 曾华. 高等教育:文化资本再生 的路径选择[J]. 南通职业大学学报,2009,(01):26-31.

Zhong Hanghong, and Zhang Yeqing. 2011. "The Impact of Family Cultural Capital on the Equality of Higher Education-Empirical Study Based Three Universities." Journal of China Electric Power Education no. 25: 7-10. 钟昌红, 张叶青. 家庭文化 资本对高等教育公平的影响一基于 3 所高校的实证研究 $[\mathrm{J}]$. 中国电力教 育,2011,(25):7-10. 